\title{
HEALTH CARE SEEKING BEHAVIOUR OF NON-FATAL ROAD TRAFFIC INJURY VICTIMS IN KERALA, INDIA
}

\author{
Godwin S.K PhD ${ }^{1 凹(D)}$, Varatharajan D PhD ${ }^{2}$ \\ ${ }^{1}$ Associate Professor, Department of Economics, Government College for Women, Thiruvananthapuram, \\ Kerala, India - 695014. \\ ${ }^{2}$ Health Economist, Health Financing and Policy, Health System Financing, World Health Organisation, 20, \\ Avenue Appia, 1211, Geneva 27, Switzerland.
}



Received 5 August 2021

Accepted 20 August 2021

Published 31 August 2021

\section{CorrespondingAuthor}

Godwin S.K PhD, godwinsk@yahoo.com DOI

10.29121/granthaalayah.v9.i8.2021. 4180

Funding: This research received no specific grant from any funding agency in the public, commercial, or not-for-profit sectors.

Copyright: (C) 2021 The Author(s). This is an open access article distributed under the terms of the Creative Commons Attribution License, which permits unrestricted use, distribution, and reproduction in any medium, provided the original author and source are credited.

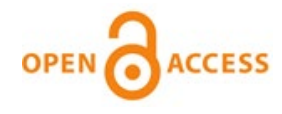

\section{ABSTRACT}

Road traffic injuries represent a classic case of economic uncertainty for households. In the context of uncertainty, choice of health care facilities and care seeking process is interest of perennial concern. Understanding the injury care seeking process forms the central objective of the paper. It also tries to narrate the process of seeking care between different providers of care, levels of care and duration of treatment, determinants of choice of health care etc. The study utilised primary data collected from the injured (302 cases) who were discharged from selected public and private health facilities from three districts of Kerala, India. The injured had 488 overall interactions with medical care institutions/personnel yielding an average number of 1.6 interactions per injured person; 60.2 per cent of the interactions were accounted by public health care institutions with 54 per cent of the injured choosing them as their first point of contact. Length of treatment at different health facilities by the injured indicate that more than 70 per cent were treated as outpatient (including observation cases) and the rest were prescribed hospitalized treatment at the first pint of contact. Share of public sector health care institutions treating mild, moderate and severe injuries is 55.5 per cent, 54.6 per cent and 48.6 per cent respectively. In sum, public sector is the preferred choice of injury care seeking for moderate and severe road traffic injuries (cost of treatment, poor economic status) while mild injuries are primarily accounted for by the private sector.

Keywords: Health Care Seeking, Non-Fatal Road Traffic Injuries, Kerala, India

\section{INTRODUCTION}

\subsection{CONTEXT}

Human beings' material progress has attained unprecedented heights especially during the last century largely promoted by increasing physical mobility. Road Traffic Accidents (RTAs) are generally considered as a price of material progress of human beings. Historically motor vehicle accidents have been believed as 'accidents', random events that are inevitable outcomes of road transport (Gumber 1994; WHO 2002). However, the mobility has not been costless and over the decades, the world has lost · millions of human lives. It is estimated that more than 30 million individuals lost their lives and the hopes of the 30 million's dependants perished on roads since the first pedestrian casualty reported in 1898 (IFoRCaRC 1998). 
A total of 4,37,396 road accident cases were reported in which 1,54,732 deaths and 4,39,262 persons injuries during 2019 (NCRB 2020). India has one per cent of the total number of vehicles in the world but accounts for six per cent of RT As. Road traffic injury is the sixth most common cause of death in India and is also more frequent among the younger groups (Peters et al 2002) and prevalence of RTI related disability is estimated to be nearly 2 million in India (Gururaj 2006). The proportion of hospitalized injuries was 3.7 for rural areas, while 4.1 per cent of the injured got hospitalized in urban areas. There is a possible inequity in the distribution of hospitalization of injured in terms of urban and rural areas. This may be possibly because of at least three reasons. First, the severity of the injury (both perceived and objective) might be higher in urban areas and so a higher hospitalization. Second, since there is a higher concentration of health facilities in urban areas, physical accessibility is lesser an issue here, and financial accessibility is also higher in urban areas as they have a higher purchasing power compared to the rural segments.

Injuries are one category of disabilities that requires long hospitalization indicating severity of the category itself and so the cost of treatment may take a huge variation compared to many other illnesses. In the 1995-96 data of NSSO (for all the major states), the incidence (per 100,000 population) of all injuries reveals that for injuries excluding hospitalization, it is 30 for India where 25 in rural and 44 in urban areas. Incidence in Kerala was 15, which is much lower than the national average, with urban areas reported zero injuries, while rural areas recorded an incidence of 19 per lakh population. Accidents/injuries account for 2 per cent of the entire outpatient cases in the country costing Rs. 500/- or USD 12.5 per episode 14 and 4 per cent of ambulatory care spending. In case of hospitalization, accidents/injuries take 16 per cent of all inpatient cases costing Rs. 9, 700/- or USD 242.50 per case and 19 per cent of all inpatient spending. Trauma accounts for 12 per cent of hospital bed occupancy and almost 7 per cent of total national health expenditures. In a hospital-based study in Kerala, India, it was seen that about 60 per cent of polytrauma (more than one organ system injury) cases were due to RTis. Injuries by type, laceration accounted for 46.7 per cent, blunt injuries (18.6 per cent) and penetrating wounds constituted 7.9 per cent. More than 34.4 per cent had head injuries while 31 per cent had long bone fractures (Devi 2005). Most studies available on the injuries are public hospital-based ones in the country, though there is evidence that large number of injury victims seek medical attention from private sector (both for-profit and not-for-profit. For example, based on the NSSO data on morbidity and ailments, in regard to injuries (but not specifically on road traffic injuries), in 1986, 25 per cent and 27 per cent of injured in rural and urban areas respectively sought inhospital treatment from private health sector, while around 79 per cent and 68 per cent respectively in rural and urban areas sought nonhospital-based treatment in the private sector (Gumber 1994). With the passage of around two decades, this share may have gone up if the later health surveys are any guide. This points towards the increased need of coordination between the public sector and private health services.

Injury care seeking is generally associated with major uncertainties concerning its incidence, care, and cure/disappearance, and the price of care. On the supply side, uncertainty in the occurrence of illness, as in the case of injuries, shrinks the choice of care and imposes higher financial burden on the affected. Though the utilization pattern of the population is shaped by social, economic, cultural and political factors, it varies widely for the rich and the poor. The poor's consumption pattern might be 
fraught with a range of sub-optimal conditions like under-dosage of medicines and foregoing of certain critical medical interventions altogether due to their inability to pay, and absence of adequate support mechanisms. When there exist price barriers to access, possible effects on equity, as obvious, is a definite negative. With regard to utilization of health services, due to both time and monetary price, the weaker sections suffer. Even though the prescription pattern of the provider is influenced by the economic status of the injured or his/her insurance status or presence of third-party financing mechanisms, there are a number of cases where due to economic constraints where the injured under-consume or even forego the consumption of required medical interventions. The process of under-utilisation or unutilisation of essential and needed interventions affects the patients to incur a higher expenditure (meaning increased 46 financial burden due to delay $\mathrm{m}$ treatment) later or worsen the health outcomes immediately or in the long run.

Understanding the injury care seeking process forms the central objective of the paper. It also tries to narrate the process of seeking care between different providers of care, levels of care and duration of treatment, determinants of choice of health care etc.

\section{METHODOLOGY}

The study tried to assess the magnitude of the above discussed components of the gross financial burden using a category of morbidity called road traffic injuries in the State of Kerala, India. A primary survey was conducted at the hospital level for the patients who had undergone treatment for injuries at different health facilities. The selection of facilities was from both public and private sources and included hospitals, nursing homes and facilities at different levels. Besides, the study undertook a 'decomposition analysis' in which the discharged patients from a health facility (both inpatients and out patients) was traced for understanding the financing of the cost of treatment, utilisation pattern, the nature of the financing method, costs of 'responses' adopted to manage the treatment of injuries, and its implications of household economic security etc within a given geographical limit.

The study used a prospective study design with injured cases undergoing treatment in a health facility (both IP and OP) were requested for their consent. A 'decomposition analysis' was undertaken in which RTI patients were traced back to their households for understanding the household chemistry of injury care financing, utilization pattern, and coping methods and their overall impact on household economic security. Information on socio-demographic characteristics, external causes of injury, situation and context of injury, help-seeking pattern and outcome was also gathered.

Household interview schedule included household characteristics such as $\mathrm{HH}$ head, HH size, assets held (land holdings), major source of income, monthly household and per capita expenditure, caste/tribe status and individual characteristics such as age, sex, marital status, educational attainment, and profession. The tool also included factors responsible for the accident, duration of hospitalization, treatment, and absence from work/leisure/household activities, type of injury, health service provider, services availed, prices of different treatment items, details of expenses incurred under each provider/system, stages when the

injured did not seek care, prescribed interventions not undertaken due to paucity of resources, and sources of financing. Detailed information on the level and sources of injury care expenditure - current/past income, sale of core/optional assets, 
reimbursement by third party like employer, insurer and others too formed part of the schedule.

The chosen RTA victims were non-fatal cases already accessed the health care institutions; the ones discharged from the chosen hospitals on the day of data collection; outpatient or inpatient cares; connected to Orthopaedics, Surgical or Neurosurgery departments and from the chosen districts and taluks. In case of RTA cases, the following exclusion criteria were applied: those who did not attend any health care facility for treating injuries; those who suffered fatal injuries; those who came for review; those who continued to receive treatment from a health care facility (not discharged); those whose injury was too rare to manage in an institution; those were related to the vehicles but did not come under the purview of road traffic accidents; those who were not stable at the time discharge.

Severity of injuries was assessed based on the status of their admissions into a particular health facility. Three levels of severity were considered: • Simple injuries (generally out-patients) - Moderate injuries (in-patients) and $\bullet$ Complex injuries (undergoing ICU management). In the absence of definite treatment protocols for treating RTIs, a treatment package was defined with the help of many currently practicing physicians and it served as a benchmark for evaluating the utilization of care, induced demand and quality of care.

Study site Study sites (districts) were chosen using the indicators such as the prevalence of RTAs and RTis, RTA fatalities, and the availability of RTI infrastructure (measured by private and public bed capacity). Using these criteria, all 14 districts in the State were ranked and three broad clusters were formed. One district each from the well performing, medium performing and worst performing group of districts was included in the study. The criteria used to choose the districts are given in Table-4.1. Additional sub-criteria such as Geographic factors (low, mid or high land), presence of 4-wheeler and 2-wheeler vehicles, and road density were also used as guidelines in choosing the study districts. Finally, chosen districts were Thiruvananthapuram, Trissur and Idukky (shaded in the table). The significance of using Geographic factors lies in the association of RTAs and their associated damages with the structure of the landscape. The chosen districts are indicated by the shading of cells in Table 1. The chosen districts fell under the categories of best, medium and worst performing districts and all their taluks (sub-districts) were ranked in similar fashion. Within the best performing district, the best performing. taluk was chosen while medium performing taluk was chosen from the median performing district; lowest performing taluk was selected from the worst performing district. Choice of specific facility was based on rural-urban considerations and on the level of utilization by the injured and the ownership (only for private hospitals). For this purpose, all the hospitals in chosen taluks were classified as small, medium and large depending on their number of functioning beds and the availability of associated facilities such as CT scan, major surgical theatre, etc.

\section{FINDINGS}

The injured had 488 overall interactions with medical care institutions/personnel yielding an average number of 1.6 interactions per injured person; 60.2 per cent of the interactions were accounted by public health care institutions with 54 per cent of the injured choosing them as their first point of contact (see Table 1). The role of the public sector increased with the increase in the number of contacts. Only 2 per cent reportedly received some form of first aid at the 
site of accident. Public sector was the first contact point for 52 per cent of the injured males and 71 per cent of the injured females. 24 For the first episode of injury management (reduction of the acute state of the injury cycle), 48 per cent of the injured needed to seek care from only one provider, while around 42 per cent sought care from two providers and about 10 per cent utilized three health care facilities to treat the first episode of injury management.

\begin{tabular}{|c|c|c|c|c|c|c|}
\hline \multicolumn{7}{|c|}{ Table 1 Care seeking by the injured } \\
\hline & \multicolumn{6}{|c|}{ Point of contact (Number of persons) } \\
\hline \multirow[t]{2}{*}{ Provider } & \multicolumn{2}{|c|}{ First } & \multicolumn{2}{|l|}{ Second } & \multicolumn{2}{|c|}{ Third } \\
\hline & Male & Female & Male & Female & Male & Female \\
\hline Public & $137(51.9)$ & $27(71.1)$ & $84(62.2)$ & $19(90.5)$ & $23(88.5)$ & $4(100)$ \\
\hline Private & $127(48.1)$ & $11(28.9)$ & $51(37.8)$ & $2(9.5)$ & $3(11.5)$ & - \\
\hline Total & \multicolumn{2}{|c|}{302} & \multicolumn{2}{|c|}{156} & \multicolumn{2}{|c|}{30} \\
\hline
\end{tabular}

Distance and Time taken to reach the health care facility: Regarding the physical accessibility of health care services, 42 per cent had a first pint of contact within $5 \mathrm{~km}$ while 31 per cent reached the provider within $10 \mathrm{~km}$. Regarding the second contact point, 24 per cent sought care within $10 \mathrm{~km}$ and 54 per cent travelled up to $60 \mathrm{~km}$. Distance travelled increased for the third contact point 60 per cent had to travel up to $20 \mathrm{~km}$ and the rest had to travel more than $60 \mathrm{~km}$. About 75 per cent of the injured reached the first point of health care contact within halfan-hour from the time of the accident; 20 per cent reached within an hour. On the other hand, 78 per cent reached the second contact point within one hour and 60 per cent reached the third contact point within one hour.

Duration of treatment: Length of treatment at different health facilities by the injured indicate that more than 70 per cent were treated as outpatient (including observation cases) and the rest were prescribed hospitalized treatment at the first pint of contact. In the second point of contact, 43 per cent were administered ambulatory treatment and 57 per cent were given in-patient treatment. In the third point of contact, 90 per cent of the injured received hospitalized treatment. More than 42 per cent of the cases had duration of treatment at the first contact point in less than one hour, while a 21 per cent were put under observation for less than 24 hours and an additional 14 per cent had a length of stay of less than 5 days. Overall, 37 per cent had a length of stay of less than 24 hours, while 26 per cent had a length of stay between 2 and 7 days, while the rest 37 per cent had a length of stay of 8 or more days of hospitalised treatment (see Table 2).

Table 2 Duration of treatment

\section{Number of persons}

\begin{tabular}{|cccc|}
\hline $\begin{array}{c}\text { Time } \\
\text { (hours) }\end{array}$ & First contact point & Second contact point & Third contact point \\
\hline $\begin{array}{c}\text { Outpatient (hours) } \\
<1\end{array}$ & 123 & 6 & 0 \\
\hline
\end{tabular}




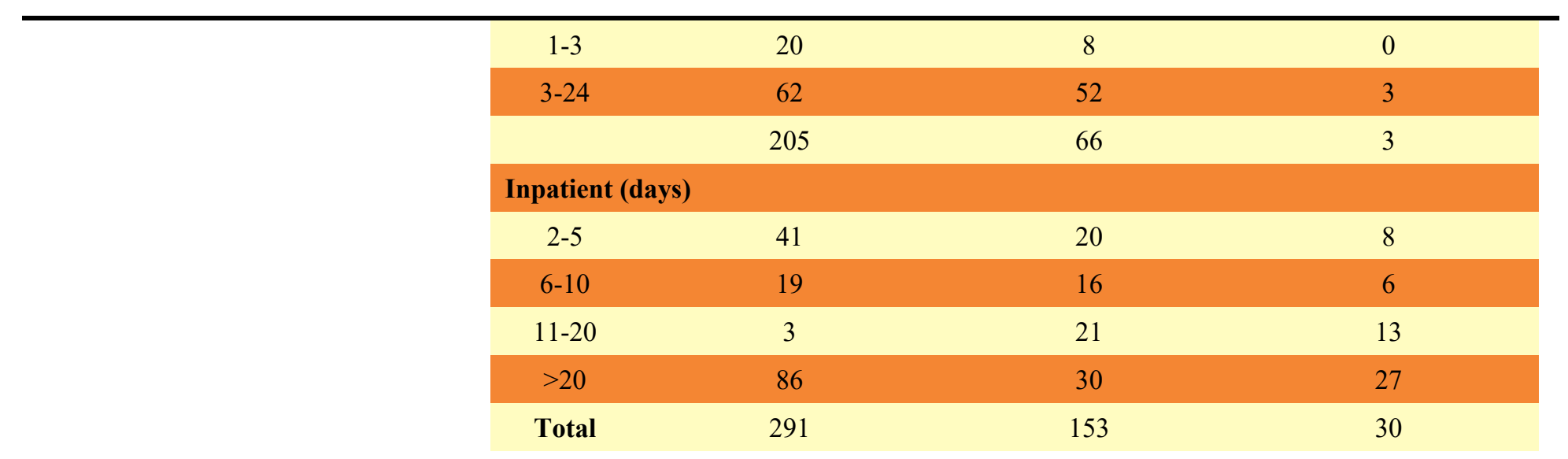

Decomposition of length of treatment across providers gives interesting results. In the first point of contact, of all patients having less than 24 hours treatment, public sector health care institutions managed about 78 per cent of cases, 46 patients having a length of stay between 2 - 7 days were treated by the public sector and 37 per cent of cases having a length of stay of 8 or above 8 days (Table $2)$. When private sector was the first point of contact, 22 per cent were given ambulatory care, 54 percent were given hospitalized treatment between 2 - 7 days and 63 per cent had a length of stay of more than 8 days. In the second point of contact, 90 per cent of the injured having a length of treatment less than 24 hours were treated in a public health care institution, while 55 per cent of cases having a length of stay of between 2 - 7 days were managed by private health care institutions and of 66 per cent of the patients having a length of stay of more than eight days were treated by private hospitals. In the third point of contact, 90 per cent of the patients were treated by public sector and the length of stay is more than 7 or more than 7 days.

Choice of health care facility for injury care: Proximity was the reason for choosing first point of contact in 65 per cent of cases, availability of specialist for 19 per cent, medico-legal issues in 7 per cent of cases and 89 cost for 6 per cent. Specialist was the reason for choosing second point of contact 51 per cent; cost was the reason for choosing the second contact point in 17 percent of cases; proximity was the reason in about 15 per cent of cases. In case of third point of contact, 60 per cent chose it because of cost and in the rest, 20 percent as well had cost as one of the factors along with proximity.

Depicting the relationship between monthly household income and type of provider finds that injured whose monthly household income is less than Rs. 2500 chose public provider in 68 percent of cases as the first point of contact, while those with monthly income above Rs.5001 chose more than 60 per cent cases a private provider. A quartile income analysis (monthly household income has been split into quartiles so as to understand the variation in financial burden borne in relation to their monthly household income) and its relationship between choice of providers reiterates the findings. There exists a statistically significant and consistent pattern in choice of providers by income quartiles. Of the 153 cases who chose only public provider, about 74 per cent belonged to the monthly household income group with less than Rs. 4,000 (USD 100) and the 26 per cent of the income group above Rs. 4,001 (USD 100 ) utilized the services of public hospitals. 


\begin{tabular}{|c|c|c|c|c|c|}
\hline \multirow{3}{*}{ Income group } & \multicolumn{5}{|c|}{ Number of injured choosing } \\
\hline & \multicolumn{2}{|c|}{ First contact point } & \multicolumn{2}{|c|}{ Second contact point } & Third contact point \\
\hline & Public & Private & Public & Private & Private \\
\hline$<2500$ & $62(68.1) *$ & $29(31.9) *$ & $28(82.4) * *$ & $6(17.6) * *$ & 6 \\
\hline $2501-5000$ & $69(54.3) *$ & $58(45.7)^{*}$ & $48(76.2)^{* *}$ & $15(23.8) * *$ & 11 \\
\hline$>5001$ & $33(39.3) *$ & $51(60.7) *$ & $27(45.8) * *$ & $32(54.2)^{* *}$ & 10 \\
\hline Total & $164(54.3)$ & $138(45.7)$ & $103(66)$ & $53(34)$ & 27 \\
\hline Significance & \multicolumn{2}{|c|}{ *At 0.001 level } & \multicolumn{2}{|c|}{ **At 0.000 level } & NA \\
\hline
\end{tabular}

Reason for leaving the health facility: It is seen from that reason for leaving the first point of health care contact was discharge in about 50 per cent of the injured, while another 45 per cent were referred to a higher-level health facility. Self-referral due to poor quality and high cost were the reasons for 3.5 per cent of all cases who attended the first point of contact. From the second point of contact, 79 per cent of the cases were discharged while a 14 per cent of the cases were further referred up to an advanced centre for care. The proportion of the injured who self-referred from the second point of contact due to poor quality and high cost went up to 7 per cent. In the third point of contact, all the patients were discharged.

Injury severity: Injury severity generally describes the impact of an injury in terms of the extent of tissue damage (that is, the pathologic evidence of trauma) and/or the physiologic response of the body to that damage (here) as perceived and reported by the injured. Choice of the injured-on providers 92 based on severity of the injury and the part of the body affected as well as the number of providers selected for the current episode of injury. The share of public sector health care institutions treating mild, moderate and severe injuries is 55.5 per cent, 54.6 per cent and 48.6 per cent respectively, whereas the share of private sector in treating mild, moderate and severe injuries is 32 per cent, 22.5 per cent and 21.4 per cent respectively. The rest of injuries were managed by public and private hospitals together, in which at least one public and one private hospital is involved. It also gives an idea regarding the segmentation of market across severity and body part affected. Secondly, the reported severity by the injured on each part is given a score with severe injury as 3 , moderate injury as 2 , simple or mild injury as 1 and no injury equals zero. Finally, the severity score of each injury group is summed and classified into two groups based on the maximum score to each group.

The maximum scores in all groups were less than 5 and 6 . So, it was comparatively easier to divide each group into two. Any group having a combined value of 2 or less than 2 is assumed as moderate injury and any group having a value of 3 or more than 3 is assumed as severe injury group. This exercise has been undertaken primarily to combine the different group of body parts as well as their 
respective severity, because road traffic 93 accidents in the study has typically more than one body part affected with differing severity.

Gap between recommended and actual interventions: Difference between recommended health care interventions and actual interventions undertaken by the injured which is alternatively called patient compliance. Majority of the recommended interventions were undertaken by the injured. Since the gap between recommended interventions and actual interventions is the least, it is assumed that the total cost of treatment in both situations would be more or less same. In the case of physiotherapy, the gap between prescribed and actual care is maximum in case of physiotherapy.

\section{DISCUSSION}

It is interesting to note that with increase in severity public sector hospital becomes the preferred option of the injured. The pattern emerges here is that the share of public and private together treating a patient increases with severity probably because the increased severity is managed by more than one institution, generally. In public health services, the referring of patients may be done according to the assessment of severity of injury by the physician and referral pattern is almost well-defined in public sector and loosely defined in the private sector. The other instances in which public sector used referral pattern were using the possibilities of backward referral (that is, after managing the acute phase of injury, some of the patients were referred back to appropriate lower-level health facilities adjacent to their residences which is justified from cost-effectiveness point of view for both the provider as well as the user (efficiency and equity gains). There were many reported instances by the injured that there exists a case selection pattern by some private health facilities who select cases (Gumber 1994) and generally do not accept and treat road traffic injury cases because of the assumed medico-legal complications. Within public sector itself, there might be a likelihood of selection of cases by the lower-level health care facilities and referring it to the higher-level facility though no concrete evidence could be found by the researcher on this aspect of the referral. If former is the case, it is not advisable because the injured might get worse off in health status terms as well as in economic terms due to over stretching of care seeking process.

Further, regarding the referral pattern across facilities, at least three significant possibilities emerge. Firstly, public sector is a preferred option of seeking care in majority of injury cases probably due to better presence, medico-legal implications, seriousness of the injury, selection of health facility often not by the injured 139 himself/herself/themselves. Also, government hospitals are usually equipped with diversified services including the surgery, orthopaedics and blood bank which many private hospitals lack (Gumber 1994). Secondly, public sector health care institutions refer a greater number of cases than private sector, which is a welcome feature if followed based on the ideal conceptualisation of referral system. But it would be disturbing and inefficient for the patient, if the lower-level public health units select cases and dump it into a higher-level centre. Thirdly, this may also show that the behaviour of some private hospitals to keep cases beyond requirement at the facility itself, which was reported by many cases. 
As far the choice of facilities and consequent economic outcome of the injury care seeking process is concerned, it is interesting to note that both the dynamics of monetary costs and time costs play a crucial role in choosing the different points of contact by the injured. In the initial stages of care seeking, more than 65 per cent sought care due to proximity reasons indicating that minimization of time costs as the dominant reason. Research finds that travel time functions as a price in determining the demand for medical services when free care is available Acton (1975). Delay in time can cost the patient both in terms of reduction in the health status as well as increase in the curative and associated expenses later on. Better spread of both public as well as private medical institutions help in the injured reaching health care facilities on time. However, it would be too simplistic to conclude that there exists no differential in care seeking from public and private. The higher income groups consistently chose private health care facilities, if not as first point of contact, at other contact points. This fact is interesting to note, because it clearly highlights the fact that even while seeking emergency care, the economic status of the victim does make a difference with higher income groups consistently chose private health care providers compared to the lower income groups whose preferred option is a public health care facility. Once the most acute phase of injury care is over, patients think of "health care provider shopping" where economic cost adequately plays its role.

Since much of the road traffic victims chose institutional care rather than individual medical practitioners, scope of doctor-shopping is limited but provider shopping is seen, at least in some cases. Medical care shopping for road traffic injury is defined as the changing of medical care institutions without professional referral for treating a single episode of road traffic injury. The reason for shopping may be price (perceived or real) and quality of treatment, among other things. The study could not reach an unambiguous answer for the pattern of shopping for institutions, rather finds that patients from higher socio-economic status chose a higher-level private hospital if the quality was perceived to be bad in a public hospital or even private hospital. Poor patients consistently chose public health facilities, assuming availability of health facilities is normal. In some study areas, it was interesting to find that due to the geographical location of a public tertiary care hospital, injury cases had to seek care from a private tertiary care centre which is known for low costs. Poor patients' shopping pattern indicates that (who are already restricted by the poor purchasing power) tend to prefer a higher-level public hospital or else adapt to the existing quality of care in the same institution if it is a public hospital.

Some interesting insights about time cost are in order. One of the general concerns is that there exists inequality even in the mode of transportation between rich and poor. For example, rich have better means of transport, and so they are able to reduce the opportunity cost of time of travel. A study from Vietnam Ensor and San (1996) finds that rich households are able to use faster modes of transport (motorcycle than bicycle or walking). However, this type of inequities in transportation of health care is not visibly noted in the present study, probably due to better spread of public and private health care institutions.

Regarding the average distance travelled by the injured to seek medical care, it is comparatively less especially in the care of an emergency event like road traffic injury which is obviously a welcome feature of the State. However, how far does it differ based on geographical region is a matter of to be probed further. Coupled with this, we observe that injured in Jdukky district are less favourably placed as majority of the injured from this district reported that they do not have a health care facility within a $3 \mathrm{~km}$ radius from their houses, which is borne true by the official data set as well. It is also crucial to note that due to better spread of both public and private 
health care facilities in most districts studied, majority of the injured have been able to reach within the 'platinum hour' and 'golden hour'. However, a number of injured reported that they had to lie unattended for not too short time. It is essential to look at options on the possibility of avoidance of acceptable delay in shifting the patient to receive appropriate medical care. It is also disturbing to note that no patient was shifted from any of the voluntary ambulance services in the studied districts, though two districts had wide presence of them. Transfer of the injured from the accident spot to the health facility was mostly done by means of unscientific mode of patient transfer, say, auto-rickshaws and cars and hardly ambulance vehicles rescued any of the injured. It calls for strengthening vehicles with appropriate life support systems. Besides, on the availability of first aid, a 98 per cent were not in receipt of any form of first aid at the site of accident which is quite disturbing. However, this may be due to the fact that health care facilitates are laterally distributed. As far as the mode of transportation to health care facility is concerned, almost all the injured were transported by car or auto rikshaws at least till the first point of contact. From first point, more number of patients was transported by ambulance to higher centres of care. In a number of cases especially in national and state highways and cases that were not attended to by any help, the police shifted them to some health care facility. However, what is expected from the police force in such events and how much actually they achieve is a question to be analysed along with. Before concluding anything regarding the accessibility to appropriate emergency medical services to the injured, it would be important to look at the fatalities associated with road traffic injuries, which the current study did not attempt to, a limitation of the current study from this perspective.

Treatment duration: Duration of treatment has demonstrated an unambiguous positive association between total injury care expenses incurred. Duration of treatment across providers and different points of health care contact illustrate that, as expected, first point of contact had the lowest cost of treatment probably reflecting: the short length of stay of critical as they would be referred upwards, less serious injuries may need the services of basic medical care consumption and mostly health facilities with small size and minimum infrastructure, In the second point of contact, majority of the injured were treated as inpatient and the length of stay was generally longer than the first point of contact implying severity of injury, assuming other things remain constant. Third point of contacts had almost all administered hospitalised treatment with more than 63 per cent having a length of stay of more than 11 days indicating that injured came to a third facility probably indicating the seriousness of the injury or absence of adequate health care infrastructure at the lower levels or higher cost of treatment of the lower-level facilities. Secondly, with regard to choose of health care facilities cases having shorter duration of treatment as well as higher duration of treatment were in a public institution. This phenomenon is interesting to observe and perhaps suggestive of the reasons: (i) Public hospitals try to treat as many cases in an ambulatory setting as possible due to the overcrowding in wards and in many cases an under-treatment could not be ruled out; (ii) Among those admitted, surgery cases had a higher length of stay skewing the length of stay picture; (iii) non-surgery cases had lesser length of stay. Private medical institutions had less variance in length of treatment across cases showing less severe cases being treated in such institutions or probably higher clinical quality. Evidence also bears out that there exists selection of cases in private health care institutions based on the expected clinical outcome of the patient before admitting the injured.

Bypassing health care facilities: The study observes the phenomenon of bypassing - i.e., when patients reject a closer facility in favour of a more distant 
health care provider. Quality reflected as specialist being the reason for choosing a distant facility is found in the study quite evidently. Existing literature mostly finds that households bypass public facilities in favour of the private sector Akin and Hutchinson (1999). We, however, find that for treating road traffic injuries many bypasses nearby private health care facilities and lower-level public facilities in favour of higher-level public-sector facilities. In general, studies have found 143 that bypassing is associated with facility quality (e.g., number of doctors, drug availability etc). However, socio-economic gradient of the individual patient concerned exerts significant influence on the choice between public and private hospitals. Bennett et al (1994) (Sonia 2002). The economic condition of the patient was also a prerequisite for admission in some of the private hospitals in the study. For instance, beyond the public health importance, some of the private hospitals admit cases on the condition that a fixed sum of amount to be deposited prior to treatment. Such ethically unacceptable practices were reported from Thailand as well Bennett et al (1994).

The study suffers from certain inherent limitations and hence, the results should be read with caution. This study was a health care institution based one and it tracked RTA victims from health care institutions. Although health care seeking is generally regarded as good in Kerala NSSO (2004), the study might have still missed injury victims who were not able to access health care institutions due to financial and other constraints. Moreover, some victims, especially in Kerala, approach alternative systems of medicine such as Ayurveda and the study missed them as well because the focus of the study was on allopathic system. Though the study reaches some conclusions regarding the choice of health care providers by the injured, the exact proportion could only be understood from a survey of households, though the study used other scientific methods to reach the maximum population.

\section{REFERENCES}

Abbs AA \& Walker GJ (1986) Determinants of the utilisation of maternal and child health services in Jordan. International Journal of Epidemiology, 15: 404407. Retrieved from https://doi.org/10.1093/ije/15.3.404

Abel-Smith B \& Rawal P. (1992).Can the poor afford 'free' health services? A case study of Tanzania. Health Policy and Planning, 7 (4): 329-341 Retrieved from https://doi.org/10.1093/heapol/7.4.329

Abel-Smith B (1994). An Introduction to Health Policy, Planning and Financing Longman Group Ltd, New York. (Chap.12; 164-177).

Acton (1975). Non-monetary factors in the demand for medical services: some empirical evidence, Journal of Political Economy, 83 (3): 595- 614. Retrieved from https://doi.org/10.1086/260342

Adam R, Stedman M, Winn J, William JI \& Ali J (1994) Improving trauma care in Trinidad and Tobago. West Indian Medical Journal. 43 (2): 36-38. Retrieved from https://europepmc.org/article/med/7941493

Aeron-Thomas (2000). Under-reporting of road traffic casualties in low-income countries, Unpublished Project Report PR/INT/199/00. TRL, Crownthorne.

Akin J. \& Hutchinson P (1999) Health care facility choice and the phenomenon of bypassing. Health Policy and Planning 14 (2): 135-51. Retrieved from https://doi.org/10.1093/heapol/14.2.135 
Amin M, Hanson K \& Mills A (2004) Price discrimination in obstetric services - a case study in Bangladesh. Health Economics 13: 597-604. Retrieved from https://doi.org/10.1002/hec.848

Andersen R et al. (1987) Health status and medical care utilisation. Health Affairs 67: 136-156. Retrieved from https://doi.org/10.1377/hlthaff.6.1.136

Arrow, KJ. (1963) Uncertainty and the Welfare Economics of Medical Care, The American Economic Review, 53 (5): 941-73. Retrieved from https://doi.org/10.1515/9780822385028-004

Barer ML (1982) Case mix adjustment in hospital cost analysis-Information theory revisited. Journal of Health Economics 1 53-80. Retrieved from https://doi.org/10.1016/0167-6296(82)90021-2

Barnum H, Kutzin J \& Saxenian H (1995) Incentives and Provider Payment Methods HRO Working Papers No. 51 March 1995. Retrieved from https://doi.org/10.1002/hpm.4740100104

Becker GS (1965) A theory of allocation of time. The Economic Journal, Vol. 75; No.299. Retrieved from https://doi.org/10.2307/2228949

Bennett S, Dakpalla G, Garner P, et al (1994) Carrot and stick: state mechanisms to influence private provider behaviour. Health Policy and Planning: 9 (1): 113. Retrieved from https://doi.org/10.1093/heapol/9.1.1

Coase R (1960) The problem of social cost. Journal of Law and Economics. 3: 1-44. 26. Corbett J (1988). Poverty and sickness: the high costs of ill health. IDS Bulletin 20 (2) 58-62. Retrieved from https://doi.org/10.1111/j.17595436.1989.mp20002008.x

Cutler DM; McClellan; Newhouse JP \& Remler D (1996). Are Medical Prices Falling? NBER Working Paper No.5750, Cambridge Retrieved from https://doi.org/10.3386/w5750

Deepa Sankar (2001). Access to health care. Unpublished PhD thesis submitted to Jawaharlal Nehru University, New Delhi. Retrieved from http://citeseerx.ist.psu.edu/viewdoc/download?doi=10.1.1.152.438\&rep= rep1\&type $=$ pdf

Dilip TR \& Duggal Ravi (2002). Incidence of non-fatal outcomes and debt in urban India: Paper presented at Urban Research Symposium, World Bank, Washington. December 2002. Retrieved from http://citeseerx.ist.psu.edu/viewdoc/download?doi=10.1.1.152.438\&rep= rep1\&type $=$ pdf

Ensor T \& San BP (1996). Health care charges and exemptions in Vietnam. Bamako Initiative Operations Programme. Research Paper No. 1. New York, UNICEF.

Ettner SL (1995). The Opportunity Costs of Elder Care. The Journal of Human 190 Resources. 31 (1). Retrieved from https://doi.org/10.2307/146047

Fabricant SJ; Kamara CW \& Mills A (1999). Why the poor pay more: household curative expenditures in rural Sierra Leone. International Journal of Health Planning and Management. 14: 179-199. 38. Feldstein PJ (1998) Health Care Economics Fifth Edition, New York: Wiley.

Retrieved

from

https://doi.org/10.1002/(SICI)10991751(199907/09)14:3<179::AID-HPM548>3.0.CO;2-N 
Gaynor. M \& Anderson GF (1995). Uncertain demand, the structure of hospital costs, and the cost of empty hospital beds. Journal of Health Economics, 14: 291317. Retrieved from https://doi.org/10.1016/0167-6296(95)00004-2

Gertler P \& Solon $O$ (2002). Who benefits from social health insurance in developing countries? (accessed on 29 Oct 2006). Retrieved from http://adfdell.pstc.brown.edu.classes/readings/gerso100.pdf

Gertler P; Locay L \& Sanderson W (1987). Are user fees regressive? The welfare implications of health financing proposals in Peru. Journal of Econometrics 36: 67-88. Retrieved from https://doi.org/10.3386/w2299

Gertler PJ (1988) A latent variable model of quality determination. Journal of Business and Economic Statistics, 6: 97-104. Retrieved from https://doi.org/10.2307/1391422

Ghee G, Silcock D, Astrop A \& Jacobs G (1997). Socio-economic aspects of road accidents in developing countries. TRL Report 247. Transport Research Laboratory, Crowthorne. Retrieved from http://worldcat.org/issn/09684107

Gilson L (1997). The lessons of user fee experience in Africa. Health Policy and Planning 12 (4): 273-285. Retrieved from https://doi.org/10.1093/oxfordjournals.heapol.a018882

GoI, NSSO (1996, 2004) Reports on morbidity and ailments in India. MoSPI, New Delhi

GoI, National Crime Records Bureau $(2000,2020)$. Accidental deaths and suicides in India, Ministry of Home Affairs, New Delhi.

Gordon, JE (1949) The Epidemiology of accidents. American Journal of Public Health. 39: 504-15. Retrieved from https://doi.org/10.2105/AJPH.39.4.504

Grossman (1972). A model of demand for health. Journal of Political Economy.72: 237-252.

Haddad S \& Fournier P (1995) Quality, cost and utilisation of health services in developing countries. A longitudinal study in Zaire. Social Science and Medicine, 40: 743-753. Retrieved from https://doi.org/10.1016/02779536(94)00134-F

Haddon, W (1980) Options for the prevention of motor vehicle crash injury. Israel Journal of Medicine. 16. 45-68. Retrieved from https://www.safetylit.org/citations/index.php?fuseaction=citations.viewd etails\&citationIds[]=citjournalarticle_588_19

Heller P (1982). A model on the demand for medical and health services in Peninsular Malaysia. Social Science and Medicine, 16: 267-84. Retrieved from https://doi.org/10.1016/0277-9536(82)90337-9

Hensher M (2001) Financing Health Systems through Efficiency Gains. Commission of Macro Economics and Health WP Series No. WG 3: 2.

Himmelstein, DU, Warren, E et al. (2005). Market Watch: Illness and injury as contributors to bankruptcy. Health Affairs (Millwood). Retrieved from https://doi.org/10.2139/ssrn.664565

Hofman K, Primack A, Keusch G \& Hrynkow (2005). Addressing the growing burden of trauma injury in low and middle-income countries. American Journal of 


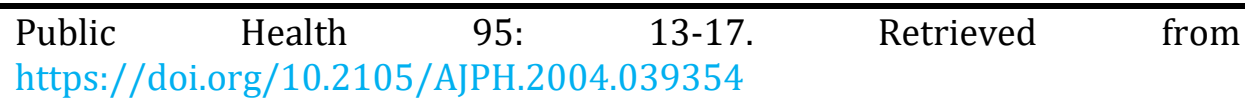

Hotchkiss DR, Hutchinson PL, Malaj A \& Berruti AA (2005) Out-of-pocket payments and utilisation of health care services in Albania: Evidence from three districts. Health Policy 30. Retrieved from https://10.1016/j. healthpol.2005.02.003

Kennedy, L, \& Dumas, MB. (1983) Hospital closures and survivals: An analysis of operating characteristics and regulatory mechanisms in three states. Health Services Research, 18 (4), 489-512. Retrieved from https://www.ncbi.nlm.nih.gov/pmc/articles/PMC1068775/

Krug EG, Sharma GK \& Lozano R (2000) The global burden of injuries. American Journal of Public Health 90 523-526 Retrieved from https://doi.org/10.2105/AJPH.90.4.523

Litvack J \& Bodart C (1993). User fees plus quality equals improved access to health care: results of a field experiment in Cameroon. Social Science and Medicine 39 (3): 35-42. Retrieved from https://doi.org/10.1016/02779536(93)90267-8

Litvack, J. \& Bodart C (1996) The Impact of raising fees and service quality: a field experiment in Cameroon', In Shaw, R P and M. Ainsworth (eds.) Financing Health Services through User Fees and Insurance, World Bank Discussion Paper No 249, Washington DC, World Bank 123-40.

Liu X \& Mills A (1999) Evaluating payment mechanisms: how can we measure unnecessary care? Health Policy and Planning; 14 (4):409-13. Retrieved from https://doi.org/10.1093/heapol/14.4.409

Lo AY, Hedley AJ, Pei GK, Ong SG, Ho LM, Fielding R, et al. (1994) 194 Doctorshopping in HongKong: implications for quality of care. International Journal of Quality Health Care 6: 371-81. Retrieved from https://doi.org/10.1093/intqhc/6.4.371

Longo, DR., \& Chase, GA. (1984) Structural determinants of hospital closure. Medical Care, 22 (5): 388-402. Retrieved from https://doi.org/10.1097/00005650198405000-00003

Lucas \& Nuwagaba (1999) Household coping strategies in response to introduction of user charges for social service: a case study on health in Uganda. IDS Working Paper 86.

Lynch, JR., \& Ozcan, YA. (1994). Hospital closure: An efficiency analysis. Hospital and Health Services Administration, 39 (2), 205-220.

Manjula Singh (2006) Exploring the perceptions of ultra poor for low utilization of micro-health insurance schemes, BRAC, Bangladesh: A Qualitative study (Unpublished Ph.D Thesis) BRAC University, Bangladesh.

Meng QY, Liu X \& Shi Junshi (2000) Comparing the services and quality of private and public clinics in rural China. Health Policy and Planning 15 (4): 349-356. Retrieved from https://doi.org/10.1093/heapol/15.4.349

Meyer JD (1985) Household survey of health expenditures, Mali. Mimeo. Agency for International Development, Washington DC.

Mock CN, Gloyd S, Adjei S, Acheampong F \& Gish O (2003) Economic consequences and resulting coping strategies in Ghana. Accident Analysis and Prevention, 


$$
\begin{array}{llll}
\text { 35: 90-91. Retrieved from https://doi.org/10.1016/S0001- } \\
\text { 4575(01)00092-6 }
\end{array}
$$

Muraleedharan, VR (1999) Characteristics and structure of the private hospital sector in urban India: a study of Madras city. Small Applied Research Paper No. 5, Partnership for Health Reform Project, Abt. Associates, Bethesda, USA. Retrieved from https://www.hfgproject.org/wpcontent/uploads/2015/02/Characteristics-and-Structure-of-the-PrivateHospital-Sector-in-Urban-India-A-Study-of-Madras-City.pdf

Murray CJL \& Lopez AD (1996) Global Health Statistics: A Compendium of Incidence, Prevalence and Mortality Estimates for Over 200 Conditions. Cambridge, Mass: Harvard University Press. Retrieved from https://pesquisa.bvsalud.org/portal/resource/pt/who-41848

Nantulya VM \& Reich MR (2002). The neglected epidemic: road traffic injuries in developing countries. BMJ; 324: 1139-41. Retrieved from https://doi.org/10.1136/bmj.324.7346.1139

Nilambar Jha, Srinivasa DK, Gautam Roy \& Jagdish S (2004). Epidemiological study of road traffic accident cases: a study from South India. Indian Journal of Community Medicine XXIX, No.1, Jan.-Mar. Retrieved from https://www.researchgate.net/profile/Sadasivan-

Jagdish/publication/45261805_Epidemiological_Study_of_Road_Traffic_Ac cident_Cases_A_Study_from_South_India/links/00b7d5151bdd205352000 000/Epidemiological-Study-of-Road-Traffic-Accident-Cases-A-Study-fromSouth-India.pdf

Odero W, Khayesi M \& Heda PM (2003) Road traffic injuries in Kenya: magnitude, cause and status of intervention. Injury Control and Safety Promotion, 10: 53-61. Retrieved from https://doi.org/10.1076/icsp.10.1.53.14103

Peden M, Scurfield R, Sleet D et al ( ed) (2004) The world report on road traffic injury prevention. World Health Organisation, Geneva.

Pramod Kumar Verma \& Tewari KN (2004). Epidemiology of Road Traffic Injuries in Delhi: Result of a Survey. Regional Health Forum 8 (1). Retrieved from https://apps.who.int/iris/bitstream/handle/10665/205798/B0031.pdf\#p age $=12$

Sahdeva P., Lacqua MJ., Singh B \& Dogra TD (1994). Road traffic fatalities in Delhi: causes, injury pattern and incidence of preventable deaths. Accident Analysis and Prevention, 26 (3) Jun 1994 p 377-384. Retrieved from https://doi.org/10.1016/0001-4575(94)90011-6

Trevino-Siller \& Hijar (2005). Mexican mass information campaign for youngsters aimed to prevent RTAs. Conference paper at 8th World Conference on Injury Prevention and Safety Promotion, Durban, South Africa March-April 2006.

Tursz A (1986) Epidemiological studies of accident morbidity in children and young people: problems of methodology. World Health Statistics Quarterly 39:257268. Retrieved from https://pubmed.ncbi.nlm.nih.gov/3788202/

Vickrey W (1968) Automobile accidents, tort law, externalities, and insurance: an economist's critique. Law of Contemporary Problems. 33: 464-487. Retrieved from https://doi.org/10.2307/1190938

Zwi AB, Fotjouh S, Murugusampillay S, Odero W \& Watts C (1996). Injuries in developing countries: policy responses needed now. Transactions of the 
Royal Society of Tropical Medicine and Hygiene 90: 593-595. Retrieved from https://doi.org/10.1016/S0035-9203(96)90399-5

van Beeck EF, Borsboom GJ \& Machenbach JP (2000) Economic development and traffic accident mortality in the industrialised world, 1962-1990. International Journal of Epidemiology, 29 (3): 503-509. Retrieved from https://doi.org/10.1093/intjepid/29.3.503 